\title{
Effect of soil management on its radioisotopic composition
}

\author{
Agnieszka Dołhańczuk-Śródka ${ }^{1}$, Zbigniew Ziembik ${ }^{1}$, Grzegorz Kusza² \\ ${ }^{1}$ Opole University, Independent Department of Biotechnology and Molecular Biology; ul. kard. B. Kominka 6, \\ 45-035 Opole, Poland; e-mail: agna@uni.opole.pl \\ ${ }^{2}$ Opole University, Department of Land Protection; ul. Oleska 22, 45-052 Opole; Poland
}

(c) 2015 Authors. This is an open access publication, which can be used, distributed and reproduced in any medium according to the Creative Commons CC-BY 4.0 License requiring that the original work has been properly cited.

Received: 30 November 2014; accepted: 17 February 2015

\begin{abstract}
Radioactive isotopes in the environment, both natural and artificial, can be good indicators in the analysis of a number of physical and chemical processes and the transport of pollutants in the ecosystem. The main aim of this study was to evaluate the impact of soil use on the radioisotopic composition in its surface layers. The radioisotopic compositions of surface soil samples, collected in the area of a cement plant, abandoned for over 20 years, as well as in the area of the nearby allotments were examined and compared. Calculations were performed using methods designed to study compositional variables. The results confirmed a significant impact of the way soil is used on the radioisotopic composition of the surface soil layers. However, some characteristics of the composition were common to both locations. It was discovered, that a significant proportion of the lead isotope $\mathrm{Pb}-210$ was derived from atmospheric deposition. Other radioisotopes remained relatively close to equilibrium in their decay chains.
\end{abstract}

Keywords: radioisotopes, soil use, compositional data analysis

\section{INTRODUCTION}

Radioactive isotopes are ubiquitous in the environment. A large part of them is a natural component, thereof, and does not pose a threat to living organisms. However, due to natural factors or human activity, these isotopes can become concentrated, and, as such, become dangerous (Borrego et al. 2007, Peroni et al. 2012, Abdel Rahman et al. 2013).

As a result of failures in power equipment, a significant amount of radioactive isotopes can be released. An example would be an event that occurred in the NPP in Chernobyl (1986) and in Fukushima (2011) (UNSCEAR 2000; UNSCEAR 2014). Significant amounts of radioactive substances are released into the environment with leachate from landfills of waste radioactive materials. Failure of various devices that use radioactive materials and failure to comply with the procedures for radioactive materials can lead to these episodes (Eisenbud \& Gessel 1997, Strand et al. 1999, Copplestone et al. 2000, Oughton et al. 2000, Smith et al. 2007, Gauthier-Lafaye et al. 2008). The main types of human activities, that cause an increase in the active concentration of natural radionuclides in the environment, include coal and metal- ore mining, fossil fuels combustion in energy production and mineral phosphate fertilizer production. Much less significant are petroleum and natural gas mining and processing, iron, non-ferrous and rare earths metals processing, and production of construction materials (Bem 2005). The occurrence of radioactive substances in the environment can also be the result of illegal activities, including, for example, abandonment of materials smuggled across state borders outside landfills (Duftschmid 2002, McDonald et al. 2004, Burr et al. 2007, Smith et al. 2008, Voytchev et al. 2009). 
Another source of radionuclides in the environment is dust arising after nuclear test explosions carried out in large numbers, especially in the late 1950's and 1960's. This dust, gradually falling, covered the entire surface of the Earth (Simon 2004, Tsumune et al. 2011).

Developing and expanding research on radioactive contamination of the environment is important for radiological and environmental purposes. Awareness of the potential risks, arising from systematic and accidental release of radioactive materials, justifies the need for extensive research regarding the retention, migration and circulation in the trophic chain and the impact of radioactive isotopes on the biosphere. Some isotopes are particularly problematic for the environment, due to their long half-life, easy migration in trophic chains or high bioavailability.

Migration paths of radionuclides in the environment are worth understanding, not only because of their potential harmfulness. Radioactive isotopes, both natural and artificial, may be convenient indicators that can be used to study a number of physical and chemical processes and transport of pollutants in the ecosystem. In particular, the simultaneous determination of certain isotopes, as well as the analysis of their relationships in a variety of materials can provide information about matter circulation in the environment.

Cumbersome substances made in various industrial processes, can, at large, enter the soil. They are converted therein, transported between the levels of soil and transferred to other components of the environment. For example in food, they can get into living organisms.

Because of the availability of the samples, using the soil for test is relatively easy. However, the specific features of the soil, characteristic to its type and characteristics of the environment, may significantly affect the transport mechanisms of the matter and, thus, significantly impede drawing conclusions from the research results. Research of the industrial impact on the environment was carried out by many authors (e.g. Cevik et al. 2007, Dai et al. 2007, Wang Lu 2007, Psichoudaki \& Papaefthymiou 2008, Papastefanou 2010). Research was mainly conducted on the content of natural radionuclides, which arise in a variety of industries where fossil fuels are burned. To determine the current deposition of natural radioactive isotopes,
K-Parameter was used, inter alia, , which is the ratio of the activity of radionuclides in the surface layer in the range from 0 to $15 \mathrm{~cm}$, as well as layer $B$ in the range of 15 to $30 \mathrm{~cm}$ (Bem et al. 2002, Dai et al. 2007, Charro 2013).

The main aim of the described study was to evaluate the impact of the soil use on the radioisotopic composition of its surface layers. The isotopic compositions of surface soil samples collected in areas used in a different way were examined and compared. The first is the area of a cement plant abandoned for over 20 years. Due to the usage of the area, the surface layer of the soil remains intact or violations are relatively small. The second area is made up of allotments. During the intensive cultivation of the soil, the surface layer is seasonally intensely mixed. Along with the gathered crop, many components of the soil are removed. However its fertilization may introduce more other components.

\section{METHODS}

The basics of the methods applied in the data processing and in the interpretation of the results are described. A mass concentration in a multicomponent system is defined by the relationship:

$$
\mathbf{c}=\left[\frac{k_{s} c_{1}}{\sum_{j=1}^{D} c_{j}}, \frac{k_{s} c_{2}}{\sum_{j=1}^{D} c_{j}}, \ldots, \frac{k_{s} c_{D}}{\sum_{j=1}^{D} c_{j}}\right]
$$

where $\mathbf{c}$ is the vector with component parts $c_{j}$ and $k$ depending on the units of measurement (usual $k$ values are 1 for proportions, 100 for $\%$, $10^{6}$ for ppm and $10^{9}$ for ppb).

Mass concentration of a radioisotope is related to its specific activity concentration in a material sample. Mass fractions $c$ of a radionuclide were calculated from the formula:

$$
c=\frac{t_{1 / 2} M}{\ln 2 N_{\mathrm{A}}} a
$$

where $t_{1 / 2}$ is the half-life time of the radionuclide, $M$ is its molar mass and $N_{\mathrm{A}}$ is Avogadro constant, $a$ is activity concentration of radionuclide. 
Studies of relationships between concentrations require utilization of appropriate methods to avoid false or delusive statistical inferences (Aitchison 2003, Aitchison \& Egozcue 2005, Aitchison 2010, Pawlowsky-Glahn \& Buccianti 2011).

The compositional data are always positive and range from 0 to a constant. Concentrations are related to each other. If content of one of the components increases, the others must decrease proportionally. Concentrations can be represented in a multidimensional space. Because of their specific properties, the simplex can be chosen for sample space.

The particular properties of compositional data preclude the application of standard statistical techniques in their raw form. In analysis of relationships between radioisotope concentrations, the methods designed for compositional data analysis were used. In analysis of the covariability of 2 variables, the Pearson correlation coefficient was usually used. However, this method may lead to false conclusions if applied to concentrations (Jackson \& Somers 1991, Aitchison 2003, Filzmoser \& Hron 2008). The covariability of components $\mathrm{A}$ and $\mathrm{B}$ can be estimated with a $V R$ parameter, calculated from the formula (Aitchison 2010, Hron \& Kubáček 2011):

$$
V R=\operatorname{var}\left(\ln \frac{\mathbf{c}_{\mathrm{A}}}{\mathbf{c}_{\mathrm{B}}}\right)
$$

where $c_{A}$ and $c_{B}$ are vectors of the A and B component concentrations, and "var" calculates variance of the logarithmised concentration ratios.

A low $V R$ value suggests similar trends of changes in A and B abundances. Such results correspond to a correlation coefficient drawing reaching near 1 . A high $V R$ may indicate a negative correlation, but this conclusion is ambiguous. Nonlinear relationships between A and B abundances may also produce high $V R$ values.

The statistical calculations were carried out in an $\mathrm{R}$ language environment and some supplemental libraries ( $\mathrm{R}$ Development Core Team 2014). In compositional data analysis, functions from library "compositions" were utilized (van den Boogaart \& Tolosana-Delgado 2013, van den Boogaart et al. 2014).

In the data analysis, clustering methods were utilized. These methods allowed us to assign a point to different groups of points (clusters), so that the data in each subset display some common traits. An overview of cluster existence in data can be shown in a tree diagram (dendrogram), illustrating the arrangement of points and clusters. For dissimilarities, the Aitchison distances, $d_{a}$, between points were selected. These distances were calculated using the formula (Pawlowsky-Glahn \& Buccianti 2011):

$$
\begin{gathered}
d_{a}\left(\mathbf{c}_{\mathrm{A}}, \mathbf{c}_{\mathrm{B}}\right)=\sqrt{\frac{1}{D} \sum_{j<l}\left(\ln \frac{c_{\mathrm{A} j}}{c_{\mathrm{A} l}}-\ln \frac{c_{\mathrm{B} j}}{c_{\mathrm{B} l}}\right)^{2}}= \\
=\sqrt{\sum_{j=1}^{D}\left(\ln \frac{c_{\mathrm{A} j}}{g\left(\mathbf{c}_{\mathrm{A}}\right)}-\ln \frac{c_{\mathrm{B} j}}{g\left(\mathbf{c}_{\mathrm{B}}\right)}\right)^{2}}
\end{gathered}
$$

where $g(\mathbf{c})$ is the geometrical mean of concentrations.

Diagrams were constructed using agglomerative and divisive algorithms, using "agnes" and "diana" functions from the "cluster" library (Maechler et al. 2014). Functions available in this library were described by Kaufman \& Rousseeuw (2005).

To obtain information about the relationships between the concentrations, Principal Component Analysis (PCA) was performed. This is a statistical procedure, in which a set of observations is converted into a set of values of linearly uncorrelated variables, called principal components, PC. The principal components are orthogonal, because they are the eigenvectors of the symmetric covariance matrix. The first principal component has the largest possible variance. Each of the next PC's has lower variance than the preceding one.

For the analysis, the concentrations were converted with a centered logratio transformation, clr, defined by the relationship (Aitchison 2003):

$$
\operatorname{clr}(\mathbf{c})=\left[\log \frac{c_{1}}{g(\mathbf{c})}, \ldots, \log \frac{c_{D}}{g(\mathbf{c})}\right]
$$

The results obtained can be illustrated in the biplot. In the graph, contributions of system components in the first 2 principal components, $\mathrm{PC} 1$ and $\mathrm{PC} 2$, are illustrated. Though interpretation of compositional biplots is different than the classical ones, they provide information about the covariability between the concentrations studied (Aitchison \& Greenacre 2002). In the compositional biplot, the 
short distance between the arrow heads represents a positive covariability in concentration's changes.

The surface soil samples, from depth between $0-30 \mathrm{~cm}$, were collected in the area of the former cement plant "Bolko", situated in southeastern periphery of Opole, Poland. After over 70 years of cement production, this plant was closed in 1978. The allotments are situated, in the distance of approx. $1.5 \mathrm{~km}$ in the northern direction from the industrial area. From these areas, 6 soil samples from each were also collected (Ziembik et al. 2012).

The activity concentrations of natural and artificial isotopes were determined using gamma spectrometry. The measurement of activity concentrations of radioisotopes in the samples of soil was carried out by means of a gamma-spectrometer, with a germanium detector HPGe (Canberra) of high resolution. Energy and efficiency calibration of the gamma spectrometer was performed with the standard solution type MBSS 2 (Czech Metrological Institute, Praha). The measuring process and analysis of spectra were both computer controlled with the use of software GENIE 2000.

\section{RESULTS}

The following radioisotopes were determined in soil samples: Ac-228, Pb-212, Bi-212 (thorium decay chain), Ra-226, $\mathrm{Pb}-214, \mathrm{Bi}-214, \mathrm{~Pb}-210$ (radium decay chain), U-235, Th-231, Bi-211 (actinium decay chain), K-40 and artificial Cs-137. In Table 1, the half-life times of the radioisotopes determined are shown.

Among the radioisotopes determined in soil samples, K-40 is the most stable. Half-life time of 1 day order characterizes Th-231. The Bi-211 isotope is the most unstable, with half-life time magnitude of minutes.

In Figure 1 boxplots describing measurements results and their statistical characteristics are shown. Interpretation of the box diagram elements is illustrated in the frame, located at the top of Figure 1 (Tukey 1977, Chambers et al. 1983).
The highest activity concentrations were measured for the $\mathrm{K}-40$ radioisotope. Though its halflife time is the longest among the radioisotopes determined, its content in soil is big enough to make $\mathrm{K}-40$ the main source of ionizing radiation in the material studied. The next, among the biggest activity concentrations, is delivered by Cs-137, an artificial isotope which contaminates the investigated region. It appeared mainly after the accident in Chernobyl NPP and still resides in the environment.

The activity concentrations of the radioisotopes belonging to the same decay chains are not extensively different from each other. Short living radioisotopes from the same decay series, for example $\mathrm{Bi}-214$ and $\mathrm{Pb}-214$, reach equilibrium in a short amount of time. Differences in activity concentrations of radionuclides with longer half-life times indicate possible soil composition changes. For example, deposition of the material enriched with radioisotopes can disturb prior equilibrium between radionuclides. Similar results can produce selective leaching of soil components. The observed moderate deviations from equilibrium suggest the occurrence of phenomena that change the surface soil composition.

After the recalculations of activity concentration to mass fractions, cluster analysis methods were applied to find possible groups in data points. Coordinates of each point are expressed by their radioisotopes content. The dissimilarities between points, represented by distances in the simplex space, were calculated, and the results were used in the dendrogram construction. In Figure 2, the dendrogram constructed with the agglomerative algorithm is shown. The branches of the dendrogram are described by "Bo" for abandoned cement works "Bolko", and by "AG" for the allotment gardens. In the vertical axis, the dissimilarities between the points and clusters are shown. The points and dendrogram segments located at the bottom of the graph represent points and groups of points located relatively close to each other.

Table 1

Half-life times of the radioisotopes determined in soil samples

\begin{tabular}{|c|c|c|c|c|c|c|c|c|c|c|c|}
\hline Ac-228 & Pb-212 & Bi-212 & Ra-226 & Pb-214 & Bi-214 & Pb-210 & U-235 & Th-231 & Bi-211 & K-40 & Cs-137 \\
\hline $\begin{array}{c}6.15 \\
\mathrm{~h}\end{array}$ & $\begin{array}{c}10.64 \\
\mathrm{~h}\end{array}$ & $\begin{array}{c}25 \\
\min \end{array}$ & $\begin{array}{c}1600 \\
\mathrm{a}\end{array}$ & $\begin{array}{c}26.8 \\
\min \end{array}$ & $\begin{array}{c}19.9 \\
\min \end{array}$ & $\begin{array}{c}22.2 \\
\mathrm{a}\end{array}$ & $\begin{array}{c}703.8 \\
\times 10^{6} \mathrm{a}\end{array}$ & $\begin{array}{c}25.52 \\
\mathrm{~h}\end{array}$ & $\begin{array}{c}2.14 \\
\min \end{array}$ & $\begin{array}{c}1.25 \\
\times 10^{9} \mathrm{a}\end{array}$ & $\begin{array}{c}30.1 \\
\mathrm{a}\end{array}$ \\
\hline
\end{tabular}


Some trends to points clustering can be observed in the dendrogram. However, it is not clear if the observed weak clustering is related to the sampling site or not. Groups of points representing "Bolko" area are divided into 2 clusters. The first cluster, located at the bottom-left part of the graph, represents points which are located close to each other in a simplex space. The second cluster represents 2 points, of which the distance from the first cluster is the biggest. These 2 clusters are separated by the groups of points representing the "AG" area, which are dispersed in a lower range than the points representing the "Bolko" area. Application of the divisive grouping method produced a similar dendrogram, leading to similar conclusions.

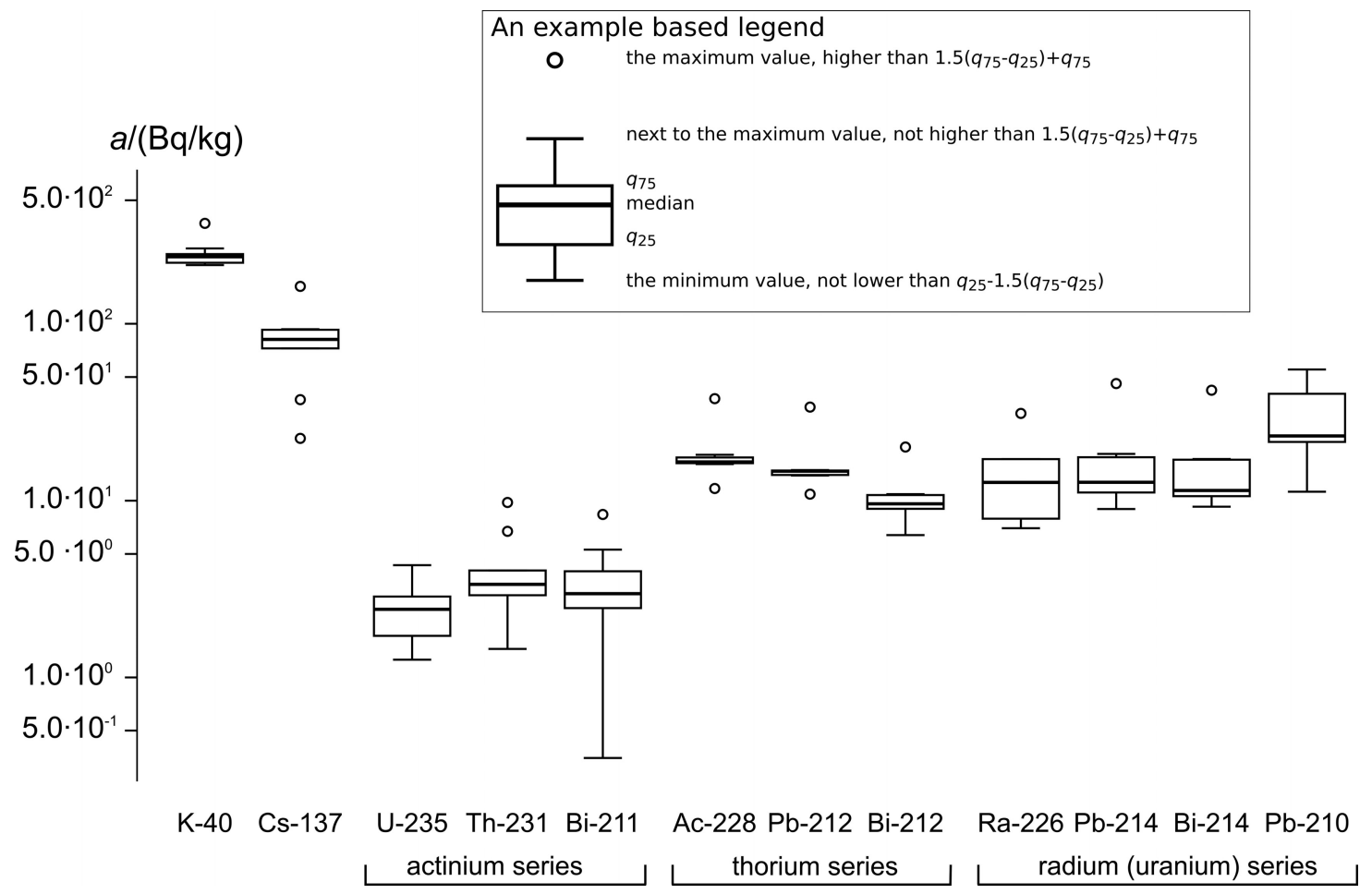

Fig. 1. Boxplots of specific activity concentrations of radioisotopes determined in soil samples

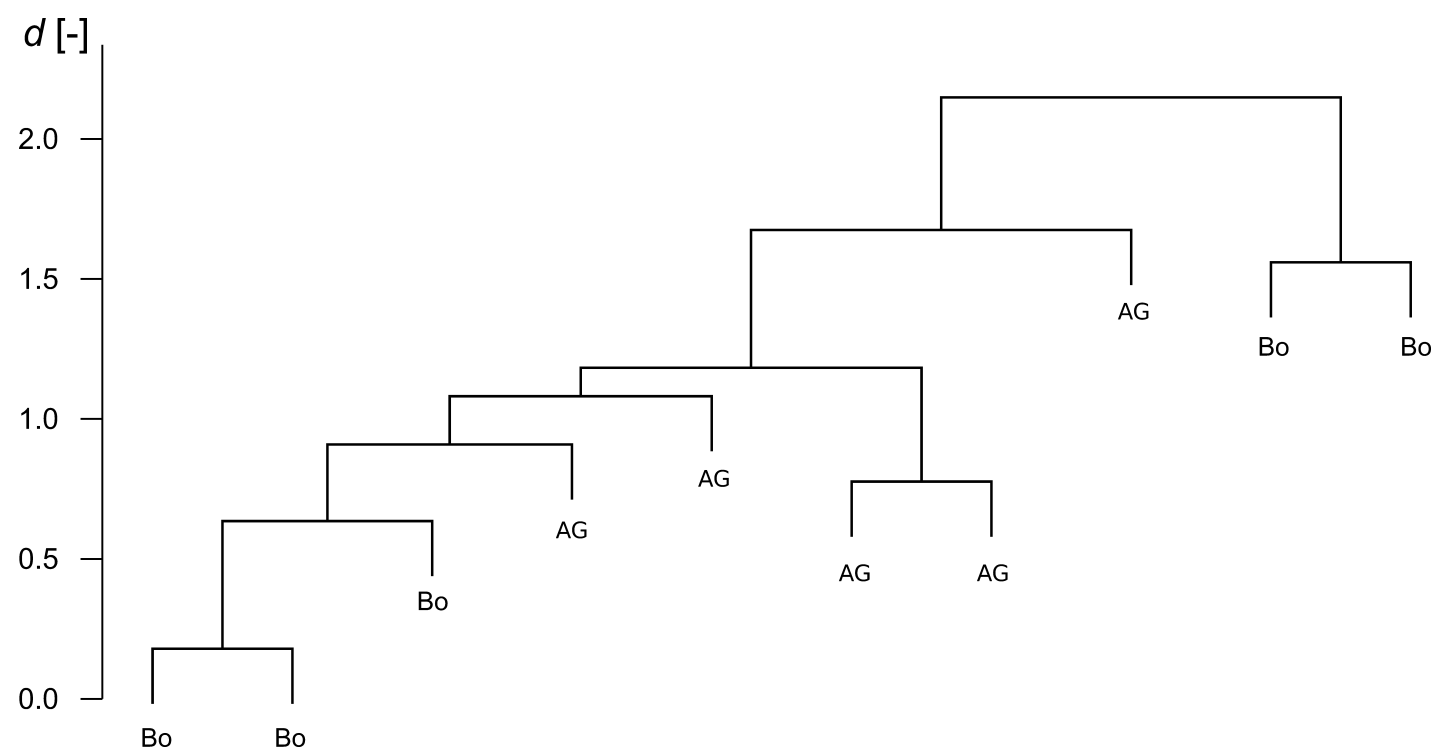

Fig. 2. Dendrogram of cluster structures in radioisotopes concentrations constructed using the agglomerative algorithm 
Table 2

Values of the VR coefficients calculated for pairs of concentrations. The VR results calculated from "Bolko" are shown in the diagonal below, composed of zeros. The upper diagonal is made up of the values calculated from the allotments results

\begin{tabular}{|l|c|c|c|c|c|c|c|c|c|c|c|}
\cline { 2 - 13 } \multicolumn{1}{c|}{} & K-40 & Cs-137 & U-235 & Th-231 & Bi-211 & Ac-228 & Pb-212 & Bi-212 & Pb-214 & Bi-214 & Pb-210 \\
\hline K-40 & 0.00 & 0.46 & 0.09 & 0.30 & 0.09 & 0.07 & 0.06 & 0.06 & 0.17 & 0.14 & 0.31 \\
\hline Cs-137 & 0.01 & 0.00 & 0.22 & 0.84 & 0.61 & 0.27 & 0.27 & 0.24 & 0.16 & 0.16 & 0.05 \\
\hline U-235 & 0.07 & 0.08 & 0.00 & 0.50 & 0.29 & 0.05 & 0.06 & 0.04 & 0.07 & 0.06 & 0.09 \\
\hline Th-231 & 0.13 & 0.23 & 0.24 & 0.00 & 0.11 & 0.26 & 0.23 & 0.27 & 0.39 & 0.35 & 0.84 \\
\hline Bi-211 & 1.16 & 1.00 & 1.55 & 1.55 & 0.00 & 0.15 & 0.12 & 0.14 & 0.29 & 0.24 & 0.56 \\
\hline Ac-228 & 0.01 & 0.01 & 0.10 & 0.15 & 0.97 & 0.00 & 0.00 & 0.00 & 0.03 & 0.02 & 0.20 \\
\hline Pb-212 & 0.00 & 0.01 & 0.07 & 0.15 & 1.05 & 0.00 & 0.00 & 0.00 & 0.04 & 0.02 & 0.21 \\
\hline Bi-212 & 0.02 & 0.00 & 0.09 & 0.22 & 0.94 & 0.01 & 0.01 & 0.00 & 0.03 & 0.02 & 0.18 \\
\hline Pb-214 & 0.02 & 0.01 & 0.07 & 0.19 & 1.00 & 0.01 & 0.01 & 0.01 & 0.00 & 0.00 & 0.12 \\
\hline Bi-214 & 0.02 & 0.01 & 0.08 & 0.18 & 0.97 & 0.01 & 0.00 & 0.01 & 0.00 & 0.00 & 0.12 \\
\hline Pb-210 & 0.06 & 0.02 & 0.08 & 0.36 & 1.00 & 0.06 & 0.05 & 0.03 & 0.04 & 0.04 & 0.00 \\
\hline
\end{tabular}

Relationships between pairs of radioisotope concentrations were examined using the $V R$ parameter. In Table 2, values of the $V R$ coefficients calculated for pairs of radioisotope concentrations are shown. The coefficients were calculated separately for the radionuclide concentrations in samples collected in the "Bolko" area and in the allotments.

Some of the $V R$ values are different for both types of land usage. For example, concentrations of K-40 and Cs-137 are quite well correlated in the "Bolko" area, while very poorly related to each other in the allotments. For the Th-231 and $\mathrm{Bi}-211$, a significant change in the $V R$ value was also observed but, in contrast to the K-40 and Cs-137 relationship, in the allotments, a stronger correlation was observed. For some other radioisotopes, a good correlation between the concentrations was observed in the abandoned industrial area and in the allotments. For example, the $V R$ values calculated for pairs of isotopes from the thorium series were small in both areas.
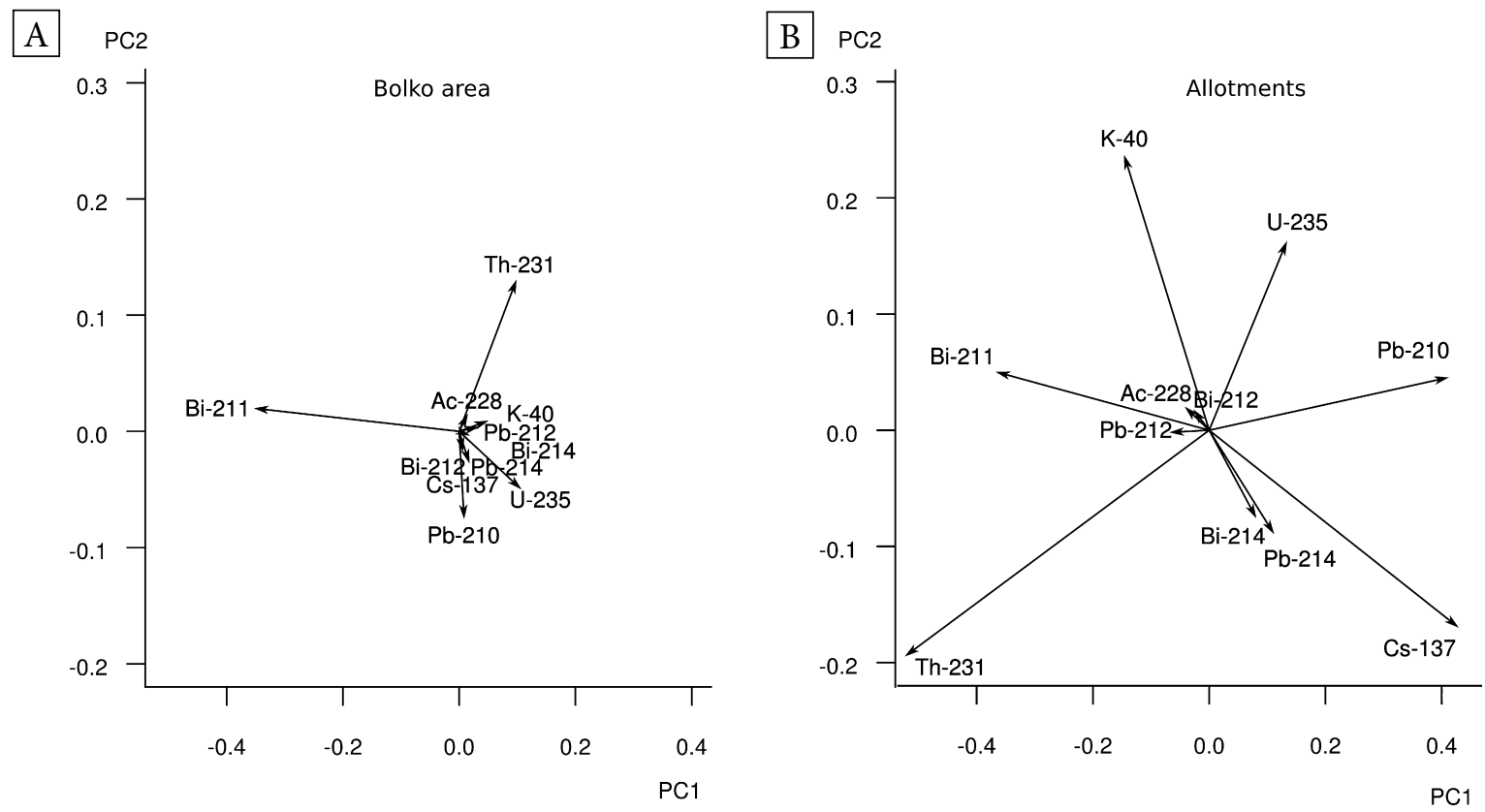

Fig. 3. Biplots illustrating relationships between radioisotope concentrations in soil samples from the "Bolko" area. In graph B the magnified central part of graph $A$ is shown 
In Figures 3 and 4 , biplots illustrating the results of PCA for "Bolko" and "Allotments" are respectively shown. In Figure 3A biplot of concentration contributions in principal components is illustrated, and in Figure3B the magnified central part of graph A is shown. Because the concentration of Ra-226 in 5 samples was lower than the detection limit, this isotope was excluded from the analysis.

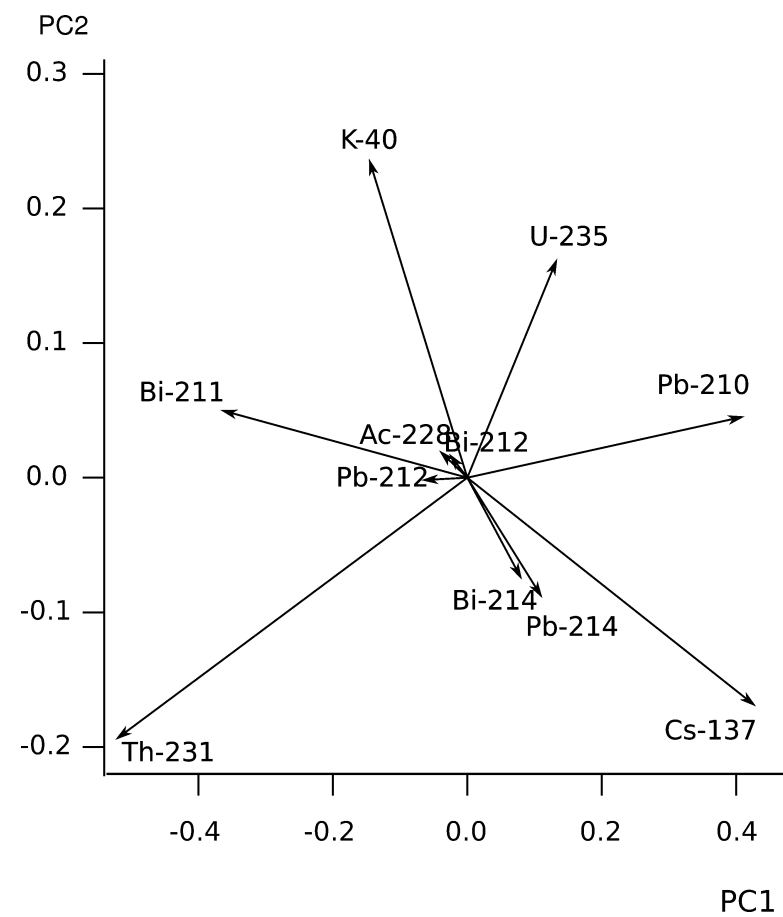

Fig. 4. Biplot illustrating relationships between radioisotope concentrations in soil samples from the "Allotments" area

The biplots confirm the conclusions drawn from the $V R$ values. In both the "Bolko" and the allotment areas, concentrations of the radioisotopes from the thorium series were nearly proportional, as indicated by low distances between the appropriate arrow heads. In the radium series, concentrations of $\mathrm{Bi}-214$ and $\mathrm{Pb}-214$ were proportional, but the concentration of $\mathrm{Pb}-210$, came off of the constant isotope ratio. This phenomenon is particularly observed in the allotments.

Both in the "Bolko" area and allotments, concentrations of radioisotopes from the actinium series were not proportional. In wasteland and cultivated areas, equilibrium in the actinium decay series is not reached. This is a result of the long decay half times of U-235, the Th-231 ancestor and the presence of long living Pa-231 (half-life time almost 33 thousands of years), among the Bi-211 ancestors.

In the "Bolko" area, the concentration of artificial Cs-137 was related to $\mathrm{Pb}-210$. Because $\mathrm{Pb}-210$ is produced in fossil fuel combustion, the observed phenomenon could be a result of atmospheric deposition of both isotopes. In the allotments, this effect was not observed. It is possible, that periodical soil surface disturbance and atmospheric precipitation causes uneven leaching of compounds containing these radionuclides.

\section{CONCLUSIONS}

Soil composition is related to the place from which the samples were collected. However, the location is not the only factor determining radioisotopical composition.

Analysis of radioisotope content showed influence of the usage type on relationships between the gamma radioisotope concentrations. Bigger deviations from radioactive equilibrium in decay chains were observed in cultivated soils than in wastelands. In soil samples, collected in the allotments, the radioisotope ratios were significantly more differentiated than in samples from the "Bolko" area. The observed differences were probably a result of periodic soil surface mixing during agro-technical works, for example, preparation for sowing.

The composition of soil changes during cultivation. For example, some soil components are removed together with the crops, while some others are added in with fertilizers. High permeability of cultivated soil, in comparison with hardened wasteland soil surface, increases leaching of soil components.

The increased $\mathrm{Pb}-210$ concentration in soil surface, in comparison to $\mathrm{Bi}-214$ and $\mathrm{Pb}-214$, indicates atmospheric deposition. In places with a high ratio of $\mathrm{Pb}-210$ and its ancestors, significant deposition of other contaminants can be expected.

The Cs-137 concentrations were not related to concentrations of other radioisotopes. This radionuclide is still deposited from air on the soil surface, but it can be locally re-suspended by floating water from rains or by gusts of wind.

Analysis of radioisotopic soil composition can provide information about the fate of current and possible future depositions. However, deposits on 
soil surfaces can behave in different ways, hampering exact estimation of the contamination. The radioisotopes naturally appearing in soil can be helpful in studies of processes occurring in the environment.

It was shown, that the way in which soil is utilized significantly affects its radioisotopic composition.

The project was financed by the National Science Centre, based on decision number DEC-2011/03/D/ ST10/05392.

\section{REFERENCES}

Abdel Rahman R.O., Elmesawy M., Ashour I. \& Hung Y.-T., 2013. Remediation of NORM and TENORM Contaminated Sites - Review Article. Environmental Progress \& Sustainable Energy, 33, 2, 588-596.

Aitchison J., 2003. The Statistical Analysis of Compositional Data. The Blackburn Press: Caldwell, New Yersey.

Aitchison J. \& Egozcue J.J., 2005. Compositional Data Analysis: Where Are We and Where Should We Be Heading? Mathematical Geology, 37, 829-50, doi:10.1007/ s11004-005-7383-7.

Aitchison J. \& Greenacre M., 2002. Biplots of Compositional Data. Journal of the Royal Statistical Society: Series C (Applied Statistics), 51, 4, 375-92, doi:10.1111/ 1467-9876.00275.

Aitchison J., 2010. A Concise Guide to Compositional Data Analysis. [on-line:] http://www.leg.ufpr.br/lib/exe/fetch. php/pessoais:abtmartins:a_concise_guide_to_compositional_data_analy-sis.pdf [access: 15.01.2014].

Bem H., Wieczorkowski P. \& Budzanowski M., 2002. Evaluation of technologically enhanced natural radiation near the coal-fired power plants in the Lodz region of Poland. Journal of Environmental Radioactivity, 61, 191-201.

Boogaart K.G. van den, Tolosana R. \& Bren M., 2014. Compositions: Compositional Data Analysis. R Package Version 1.40-1, [on-line:] http://CRAN.R-project.org/package=compositions [access: 05.12.2014].

Boogaart K.G. van den \& Tolosana-Delgado R., 2013. Analyzing Compositional Data with R. Springer-Verlag, Berlin, Heidelberg.

Borrego E., Mas J.L., Martín J.E., Bolívar J.P., Vaca F. \& Aguado J.L., 2007. Radioactivity Levels in Aerosol Particles Surrounding a Large TENORM Waste Repository after Application of Preliminary Restoration Work. Science of the Total Environment, 377, 1, 27-35, doi:10.1016/j.scitotenv.2007.01.098.

Burr T., Gattiker J.R., Myers K. \& Tompkins G., 2007. Alarm criteria in radiation portal monitoring. Applied Radiation and Isotopes, 65, 5, 569-580.

Chambers J.M., Cleveland W.S., Kleiner B. \& Tukey B.A., 1983. Graphical Methods for Data Analysis. Wadsworth International Group, Boston.

Cevik U., Damla N. \& Nezir S., 2007. Radiological characterization of Cayirhan coalfired power plant in Turkey. Fuel, 86, 2509-2513.
Charro E., Pardo R. \& Peña V., 2013. Chemometric interpretation of vertical profiles of radionuclides in soils near a Spanish coal-fired power plant. Chemosphere, 90, 488-496.

Copplestone D., Johnson M.S., Jackson D. \& Jones S.R., 2000. Doses to terrestrial biota in the vicinity of BNFL Sellafield, Cumbria, UK. Radiation Protection Dosimetry, 92, 1-3, 177-182.

Dai L., Wei H. \& Wang L., 2007. Spatial distribution and risk assessment of radionuclides in soils around a coal-fired power plant: a case study from the city of Baoji. China. Environmental Research, 104, 201-208.

Duftschmid K.E., 2002. Over the border - the problems of uncontrolled radioactive materials crossing national borders. Journal of Radiological Protection, 22, 1, 31-43.

Eisenbud M. \& Gessel T., 1997. Environmental Radioactivity. From Natural, Industrial and Military Sources. Academic Press, San Diego, London, Boston, New York, Sydney, Tokyo, Toronto.

Filzmoser P. \& Hron K., 2008. Correlation Analysis for Compositional Data. Mathematical Geosciences, 41, 8, 905-919, doi:10.1007/s11004-008-9196-y.

Gauthier-Lafaye F., Pourcelot L., Eikenberg J., Beer H., Roux G.L., Rhikvanov L.P., Stille P., Renaud P. \& Mezhibor A., 2008. Radioisotope contaminations from releases of the Tomsk-Seversk nuclear facility (Siberia, Russia). Journal of Environmental Radioactivity, 99, 4, 680-693.

Hron K. \& Kubáček L., 2011. Statistical Properties of the Total Variation Estimator for Compositional Data. Metri$k a, 74,221-230$, doi:10.1007/s00184-010-0299-3.

Jackson DA. and Somers K.M., 1991. The Spectre of 'Spurious' Correlations. Oecologia, 86, 1, 147-151, doi:10.1007/ BF00317404.

Kaufman L. \& Rousseeuw P.J., 2005. Finding Groups in Data. An Introduction to Cluster Analysis. Wiley, New York.

Maechler M., Rousseeuw P., Struyf A., Hubert M. \& Hornik K., 2014. Cluster: Cluster Analysis Basics and Extensions. R Package Version 1.15.3.

McDonald J.C., Coursey B.M. \& Carter M., 2004. Detecting Illicit radioactive sources. Physics Today, 57, 11, 36-41.

Oughton D.H., Keith Fifield L., Day J.P., Cresswell R.C., Skipperud L., Di Tada M.L., Salbu B., Strand P., Drozcho E. \& Mokrov Y., 2000. Plutonium from Mayak: Measurement of Isotope Ratios and Activities Using Accelerator Mass Spectrometry. Environmental Science \& Technology, 34, 10, 1938-1945, doi:10.1021/es990847z.

Papastefanou C., 2010. Escaping radioactivity from a coalfired power plants (CPPs) due to coal burning and the associated hazards: a review. Journal of Environmental Radioactivity, 101, 191-200.

Pawlowsky-Glahn V. \& Buccianti A., 2011. Compositional Data Analysis.Theory and Applications. John Wiley \& Sons, United Kingdom.

Peroni M., Mulas V., Betti E., Patata L. \& Ambrosini P., 2012. Decommissioning and Remediation of NORM/ TENORM Contaminated Sites in Oil and Gas. Chemical Engineering Transactions, 28, 181-186, doi:10.3303/ CET1228031.

Psichoudaki M. \& Papaefthymiou H., 2008. Natural radioactivity measurements in the city of Ptolemais (Northern Greece). Journal of Environmental Radioactivity, 99, 1011-1017. 
R Development Core Team, 2014. R: A Language and Environment for Statistical Computing. R Foundation for Statistical Computing, Vienna, Austria, [on-line:] http:// www.R-project.org [access: 01.12.2014].

Simon S., 2004. The geographic distribution of radionuclide deposition across the continental US from atmospheric nuclear testing. Journal of Environmental Radioactivity, $74,1-3,91-105$.

Smith A.D., Jones S.R., Gray J. \& Mitchell K.A., 2007. A review of irradiated fuel particle releases from the Windscale Piles, 1950-1957. Journal of Radiological Protection, 27, 2, 115-145.

Smith D.K., Kristo M.J., Niemeyer S. \& Dudder G.B., 2008. Documentation of a model action plan to deter illicit nuclear trafficking. Journal of Radioanalytical and Nuclear Chemistry, 276, 2, 415-419.

Strand P., Brown J., Drozhko E., Mokrov Y., Salbu B., Oughton D., Christensen G. \& Amundsen I., 1999. Biogeochemical behaviour of ${ }^{137} \mathrm{Cs}$ and ${ }^{90} \mathrm{Sr}$ in the artificial reservoirs of Mayak PA, Russia. Science of The Total Environment, 241, 1-3, 107-116.

Tsumune D., Aoyama M., Hirose K., Bryan F.O., Lindsay K. \& Danabasoglu G., 2011. Transport of ${ }^{137} \mathrm{Cs}$ to the Southern Hemisphere in an ocean general circulation model. Progress in Oceanography, 89, 1-4, 38-48.
Tukey J.W., 1977. Exploratory Data Analysis. Addison-Wesley series in behavioral science. Addison-Wesley $\mathrm{Pu}-$ blishing Company, Reading.

UNSCEAR, 2000. Report, Annex J: Exposures and Effects of the Chernobyl Accident. [on-line:] http://www. unscear.org/docs/ reports/annexj.pdf [access: 02.12. 2014].

UNSCEAR, 2014. Sources, effects and risks of ionizing radiation. Annex A: Levels and Effects of Radiation Exposure due to the Nuclear Accident after the 2011 Great East-Japan Earthquake and Tsunami. New York, United Nations. [on-line:] http://www.unscear.org/unscear/en/ publications/2013_1.html [access: 07.12.2014].

Voytchev M., Chiaro P. \& Radev R., 2009. Development of international standards for instrumentation used for detection of illicit trafficking of radioactive material. $\mathrm{Ra}$ diation Measurements, 44, 1, 1-5.

Wang L. \& Lu X., 2007. Natural radionuclide concentrations in soils around Baoji coal-fired power plant, China. Radiation Effects and Defects in Solids, 162, 677-683.

Ziembik Z., Dołhańczuk-Śródka A. \& Kusza G., 2012. Preliminary Results of Studies on Radioisotopes Activity Concentrations in Vicinity of Cement Works. Proceedings of ECOpole, 6, 2, 559-563. 